\title{
CULTIVO PARA ALTO E BAIXO NITROGÊNIO EM GENÓTIPOS DE MILHO NO TOCANTINS VISANDO A PRODUÇÃO DE ÓLEO
}

Layanni Ferreira Sodré ${ }^{1}$, Sérgio Donizeti Ascêncio ${ }^{1}$, Joênes Mucci Peluzio ${ }^{1}$, Flávio Sérgio Afférri $^{1}$, Weder Ferreira dos Santos ${ }^{1}$, Edmar Vinícius de Carvalho ${ }^{1}$

${ }^{1}$ Universidade Federal Tocantins- UFT, E-mail: farm.layannisd@gmail.com, sergioda@uft.edu.br, joenesp@mail.uft.edu.br, flavioafferri@gmail.com, eng.agricola.weder@gmail.com, ed.vinicius_carvalho@hotmail.com

\section{RESUMO}

O presente trabalho foi realizado com o objetivo de identificar genótipos de milho, em cultivo sob alto e baixo nível tecnológico, para produção de óleo, em Palmas-TO. Os genótipos UFT 7, ORION, UFT 1, P29-M5 e P37-3 são recomendados para produtores que adotam baixo nível tecnológico. Os genótipos de milho P36-19, BR 205, AL BANDEIRANTE, AG 1051 e P28-2B, são indicados para produtores que utilizam alto nível tecnológico.

Palavras-chave: adubação nitrogenada, lipídeo, Zea mays

\section{FARMING FOR HIGH AND LOW NITROGEN IN MAIZE GENOTYPES IN PALMAS, TOCANTINS STATE, BRAZIL FOR OIL PRODUCTION}

\section{ABSTRACT}

The present study was realized to identify genotypes of maize cultivation under high and low technology for the oil yeld in Palmas State of Tocantins, Brazil. Genotypes UFT 7, ORION, UFT 1, P29 -M5 and P37-3 are recommended for farmers who adopt low technological level. The P36-19 BR 205, AL BANDEIRANTE, AG 1051 and P28-2B genotypes are recommended to producers using high technological level.

Keywords: nitrogen fertilization, lipid, Zea mays

\section{INTRODUÇÃO}

No Estado do Tocantins, o milho apresenta produtividade média de $4.821 \mathrm{~kg}$ ha $^{-1}$ (média da primeira e segunda safras 2015), que é inferior à média nacional 5.181 $\mathrm{kg} \mathrm{ha} \mathrm{ha}^{-1}$ (CONAB, 2015) devido, dentre outros fatores, como a altas temperaturas, a escassez de programas de melhoramento de milho para baixa altitude no estado, a seleção de genótipos para condições de baixo nível tecnológico (sem o uso de fertilizantes) (SANTOS et al., 2014).

Assim, é de extrema importância identificar genótipos de milho para uma produção agrícola mais sustentável, com vistas a redução dos custos de produção (FRITSCHE-NETO \& BORÉM, 2011). 


\section{CULTIVO PARA ALTO E BAIXO NITROGÊNIO EM GENÓTIPOS DE MILHO NO TOCANTINS VISANDO A PRODUÇÃO DE ÓLEO}

No melhoramento de plantas, para a identificação de cultivares eficientes na absorção e utilização do nutriente, é necessário estabelecer metodologias rápidas, de baixo custo e que permitam discriminar germoplasmas (FIDELIS et al., 2008).

$$
\text { Fageria \& Baligar }
$$
desenvolveram metodologia específica para estresse mineral aplicáveis ao melhoramento de plantas, para a seleção de plantas eficientes quanto ao uso dos nutrientes e responsivas à sua aplicação.

Esta metodologia tem sido bastante utilizada em ensaios de campo, uma vez que os mesmos fazem parte da rotina dos programas de melhoramento (FIDELIS et al., 2008; ROTILI et al., 2010; FIDELIS et al., 2011; FIDELIS et al., 2012). Entretanto, nenhum estudo tem sido voltado para a cultura do milho em baixas latitudes, principalmente no tocante ao $\mathrm{RO}$.

Neste sentido, o presente trabalho foi realizado com o intuito de identificar genótipos de milho no Estado do Tocantins, para a característica rendimento de óleo, para alto e baixo investimento em nitrogênio.

\section{MATERIAL E MÉTODOS}

Foram realizados dois ensaios de competição de genótipos de milho no Centro
Agrotecnológico da Universidade Federal do Tocantins (UFT), Campus de Palmas, sendo um instalado sob condições de alto nitrogênio $\left(150 \mathrm{~kg} \mathrm{ha}^{-1}\right.$ de $\left.\mathrm{N}\right)$ e um sob baixo nitrogênio $\left(0 \mathrm{~kg} \mathrm{ha}^{-1}\right.$ de $\left.\mathrm{N}\right)$. A semeadura foi realizada em 10 de dezembro de 2014.

O delineamento experimental utilizado, em cada ensaio, foi de blocos ao acaso com 18 tratamentos e três repetições. Os tratamentos foram constituídos de 18 genótipos, sendo 13 de polinização aberta (P40-8, P36-19, P29-M12, P32-11, P36-16, P28-2B, P37-3, P24-M1, P29-M5 UFT 1, UFT 5, UFT 7, UFT 4), oriundos de programas de melhoramento genético da Universidade Federal do Tocantins - UFT e cinco comerciais, sendo quatro híbridos duplos (AG 1051, BR 205, BRAS 3010 e ORION) e uma variedade (AL Bandeirante).

A parcela experimental foi composta por quatro linhas de cinco metros de comprimento, espaçadas de $0,90 \mathrm{~m}$ entre as linhas. Na colheita, foram utilizadas as duas linhas centrais de cada fileira, descartando-se 0,50m das extremidades das fileiras.

Foram realizadas as operações de aração, gradagem e sulcamento. O plantio das sementes e a adubação no sulco de semeadura foram efetuados manualmente. A adubação de pré-plantio foi realizada utilizando $300 \mathrm{~kg} \mathrm{ha}^{-1}$ de NPK e ZN, para 
todos os ensaios, sendo os demais tratos culturais efetuados assim que se fizeram necessários conforme exigência da cultura.

As adubações nitrogenadas (N) utilizadas, em cobertura, foram de 0 e $150 \mathrm{~kg}$ $\mathrm{ha}^{-1}$, respectivamente, proporcionando totais de 15 e $165 \mathrm{~kg} \mathrm{ha}^{-1}$ de $\mathrm{N}$, para os ambientes de baixo e alto $\mathrm{N}$.

A adubação em cobertura foi com ureia parcelada em duas aplicações. A primeira no estádio fenológico de quatro folhas (V4) e a segunda no de oito (V8). Os tratos culturais foram realizados sempre que necessário, de acordo com as recomendações técnicas para a cultura do milho (FANCELLI \& DOURADO NETO, 2004).

Nas duas fileiras centrais, de cada parcela, foram colhidas as espigas, no estádio R6 (maturidade fisiológica). Em seguida, as espigas foram debulhadas e os grãos acondicionados em saco de papel, o qual foi identificado por genótipo, e transportado para o Laboratório de Pesquisa em Produtos Naturais-LPPN da Universidade Federal do Tocantins Campus de Palmas. Os grãos foram moídos para determinação do teor de óleo (\%).

$\mathrm{O}$ rendimento de óleo ( $\left.\mathrm{RO} \mathrm{kg} \mathrm{ha}^{-1}\right)$ foi obtido pelo rendimento de grãos (massa de grãos de cada parcela corrigida para $13 \%$ de umidade e transformada em $\mathrm{kg} \mathrm{ha}^{-1}$ ) multiplicado pelo teor de óleo (\%), obtido pelo método de Soxhlet, segundo IAL (2005).

Para identificar genótipos eficientes quanto ao uso do nitrogênio $(\mathrm{N})$ e responsivos à sua aplicação, foi utilizada a metodologia proposta por Fageria \& Baligar (1993). Por esta metodologia, a eficiência correspondeu à média de rendimento de óleo de cada genótipo em baixo N. A resposta a aplicação do nutriente, para cada genótipo, foi oriunda da diferença de rendimento nos dois níveis de nitrogênio (alto e baixo $\mathrm{N}$ ) dividido pelo diferença entre os níveis de $\mathrm{N}$ utilizados em cobertura (Equação 1).

$$
\text { Resposta }=\frac{(R O A N-R O B N)}{D E N} \text { Equação } 1 .
$$

Onde:

ROAN = Rendimento de óleo com nível ideal de nutriente;

ROBN = Rendimento de óleo com baixo nível do nutriente, e;

DEN $=$ Diferença entre doses $\left(\mathrm{kg} \mathrm{ha}^{-1}\right)$.

Utilizou-se a representação gráfica no plano cartesiano para classificar os genótipos. No eixo das abscissas, encontrase a eficiência na utilização do $\mathrm{N}$ e no eixo das ordenadas, encontra-se a resposta à sua utilização. O ponto de origem dos eixos é a eficiência média e a resposta média dos genótipos. No primeiro quadrante são 


\section{CULTIVO PARA ALTO E BAIXO NITROGÊNIO EM GENÓTIPOS DE MILHO NO TOCANTINS VISANDO A PRODUÇÃO DE ÓLEO}

representados os genótipos eficientes e responsivos; no segundo, não eficientes e responsivos; no terceiro, os não eficientes e não responsivos e no quarto, os eficientes e não responsivos.

Após serem tabulados, os dados de RO foram submetidos ao teste de normalidade. Em seguida, foi realizada análise de variância para cada ensaio (nível de $\mathrm{N})$ e, em seguida, análise conjunta seguindo o critério da homogeneidade dos quadrados médios residuais dos ensaios.

Os índices de eficiências e respostas dos genótipos foram também submetidos à normalidade e, posteriormente, foi realizada análise de variância para cada um dos mesmos.

As médias dos genótipos, ambientes e dos índices de eficiência e resposta, foram comparadas pelo teste de grupos de (SCOTT \& KNOTT, 1974), a 5\% de significância. Foi realizada, ainda, correlação fenotípica entre os índices de eficiência e resposta dos genótipos, sendo utilizado o teste $\mathrm{t}$ ao nível de 5\% de significância.

As análises estatísticas foram realizadas utilizando o programa Computacional Genes, versão 2007 (CRUZ, 2007).

\section{RESULTADOS E DISCUSSÃO}

A análise de variância conjunta (Tabela 1) apresentou efeito significativo (p $<$ 0,05) para ensaios, genótipos e interação no RO. Esta última indica existência de comportamento diferencial dos genótipos nos diferentes ensaios. Neste sentido, foram realizados os desdobramentos, ou seja, o estudo de todos os genótipos dentro de cada ensaio e o comportamento de cada genótipo entre os ensaios.

A diferença de desempenho dos genótipos indicou a existência de variabilidade genética para rendimento de óleo. Santos et al. (2015) também observaram efeito significativo entre genótipos de milho e interação com ambiente, quanto ao rendimento de óleo.

O rendimento de óleo (Tabela 2) variou de $121 \mathrm{~kg} \mathrm{ha}^{-1}$ (Baixo N; P36-19) a $287 \mathrm{~kg} \mathrm{ha}^{-1}$ (Alto N; AG 1051), valores próximos aos encontrados por Santos et al. (2015) em 10 populações no Tocantins.

Foram formados quatro grupos de médias em Alto $\mathrm{N}(\mathrm{AN})$, onde as maiores médias foram os genótipos AG 1051, P282B, P24-M1, e as menores médias dos genótipos P40-8, P36-19, BR 205, AL BANDEIRANTE, P29-M12 e BRAS 3010. 
Tabela 1. Resumo da análise de variância conjunta para rendimento de óleo (RO), e para a eficiência e resposta, de 18 genótipos de milho, cultivadas em dois ensaios (diferentes níveis de nitrogênio), na safra 2014/2015, Palmas -TO.

\begin{tabular}{ccccc}
\hline Fonte de Variação Grau de Liberdade & RO & Eficiência & Resposta \\
\hline Bloco & 2 & - & 308,241 & $0,0001^{\mathrm{ns}}$ \\
Bloco/Ensaio & 4 & $307,23^{\text {ns }}$ & - & - \\
Ensaios & 1 & $56376,89^{*}$ & - & $72,59^{*}$ \\
Genótipos & 17 & $4242,26^{*}$ & $2847,14^{*}$ & - \\
Interação & 17 & $1504,08^{*}$ & - & \\
Erro/Conjunta & 68 & 215,82 & & 0,0018 \\
Erro/Bloco & 34 & - & 147,77 & 0,31 \\
\hline Média & & 200 & 6,8 & 13,8
\end{tabular}

*, ns: significativo e não significativo, respectivamente, pelo teste $\mathrm{F}$ a 5\%.

Já no ensaio de Baixo N (BN), foram formados quarto grupos, com os genótipos ORION, P37-3, P24-M1, P29-M5, UFT 1 e UFT 7 no grupo de maiores rendimento, e no grupo com menores rendimentos os genótipos P36-19, BR 205 e AL BANDEIRANTE.

Os genótipos P29-M12, BRAS 3010, P37-3 e UFT 7 apresentaram comportamento similar nos ensaios de BN e AN. Os demais genótipos, apresentaram maior rendimento de óleo sob AN.

Os genótipos P36-16, P32-11, P24M1, UFT-7, ORION, UFT-1, P29-M5 e P373 foram eficientes no uso de N, uma vez que 178 apresentaram as maiores médias de rendimento de óleo em $\mathrm{BN}$, sendo apresentados no primeiro e quarto quadrantes (Figura 1).

Ressalta-se que todos os genótipos, com exceção de ORION (híbrido duplo), são variedades de polinização aberta oriundas de programas de melhoramento no Estado do Tocantins, ou seja, com desenvolvimento sob condições de estresse ambiental, principalmente no tocante à temperatura elevadas e solos pouco férteis.

De modo geral, esses resultados concordam com aqueles oriundos da eficiência dos genótipos (Tabela 1). 


\section{CULTIVO PARA ALTO E BAIXO NITROGÊNIO EM GENÓTIPOS DE MILHO NO TOCANTINS VISANDO A PRODUÇÃO DE ÓLEO}

Tabela 2. Médias de rendimento de óleo $\left(\mathrm{kg} \mathrm{ha}^{-1}\right)$ em 18 genótipos de milho cultivados dois níveis de N na safra 2014/2015, Palmas - TO.

\begin{tabular}{ccccc}
\hline Genótipos & Alto N & Baixo N & Eficiência & Resposta \\
\hline P40-8 & $194 \mathrm{Ad}$ & $155 \mathrm{Bc}$ & $155 \mathrm{c}$ & $0,26 \mathrm{e}$ \\
P36-19 & $179 \mathrm{Ad}$ & $121 \mathrm{Bd}$ & $121 \mathrm{~d}$ & $0,39 \mathrm{c}$ \\
BR 205 & $199 \mathrm{Ad}$ & $133 \mathrm{Bd}$ & $133 \mathrm{~d}$ & $0,44 \mathrm{c}$ \\
AL BANDEIRANTE & $190 \mathrm{Ad}$ & $128 \mathrm{Bd}$ & $128 \mathrm{~d}$ & $0,41 \mathrm{c}$ \\
ORION & $233 \mathrm{Ab}$ & $203 \mathrm{Ba}$ & $203 \mathrm{a}$ & $0,20 \mathrm{f}$ \\
P29-M12 & $188 \mathrm{Ad}$ & $172 \mathrm{Ab}$ & $172 \mathrm{~b}$ & $0,11 \mathrm{~g}$ \\
AG 1051 & $287 \mathrm{Aa}$ & $154 \mathrm{Bc}$ & $154 \mathrm{c}$ & $0,89 \mathrm{a}$ \\
BRAS 3010 & $183 \mathrm{Ad}$ & $177 \mathrm{Ab}$ & $177 \mathrm{~b}$ & $0,04 \mathrm{~g}$ \\
P32-11 & $240 \mathrm{Ab}$ & $185 \mathrm{Bb}$ & $185 \mathrm{~b}$ & $0,34 \mathrm{~d}$ \\
P36-16 & $231 \mathrm{Ab}$ & $180 \mathrm{Bb}$ & $180 \mathrm{~b}$ & $0,34 \mathrm{~d}$ \\
P28-2B & $263 \mathrm{Aa}$ & $167 \mathrm{Bb}$ & $167 \mathrm{~b}$ & $0,64 \mathrm{~b}$ \\
P37-3 & $223 \mathrm{Ac}$ & $218 \mathrm{Aa}$ & $218 \mathrm{a}$ & $0,03 \mathrm{~g}$ \\
P24-M1 & $264 \mathrm{Aa}$ & $213 \mathrm{Ba}$ & $213 \mathrm{a}$ & $0,34 \mathrm{~d}$ \\
P29-M5 & $243 \mathrm{Ab}$ & $218 \mathrm{Ba}$ & $218 \mathrm{a}$ & $0,17 \mathrm{f}$ \\
UFT 1 & $248 \mathrm{Ab}$ & $219 \mathrm{Ba}$ & $219 \mathrm{a}$ & $0,19 \mathrm{f}$ \\
UFT 5 & $214 \mathrm{Ac}$ & $175 \mathrm{Bb}$ & $175 \mathrm{~b}$ & $0,26 \mathrm{e}$ \\
UFT 7 & $216 \mathrm{Ac}$ & $196 \mathrm{Aa}$ & $196 \mathrm{a}$ & $0,13 \mathrm{f}$ \\
UFT 4 & $216 \mathrm{Ac}$ & $176 \mathrm{Bb}$ & $176 \mathrm{~b}$ & $0,26 \mathrm{e}$ \\
\hline Média & $223 \mathrm{a}$ & $177 \mathrm{~b}$ & 177 & 0,31 \\
\hline
\end{tabular}

Médias seguidas por mesma letra maiúscula na linha e minúscula na coluna, pertencem a um mesmo grupo, de acordo com o critério de agrupamento de Scott \& Knott (1974), a 5\% de significância. Alto N = $150 \mathrm{~kg} \mathrm{ha}^{-1}$; Baixo N $=0 \mathrm{~kg} \mathrm{ha}^{-1}$

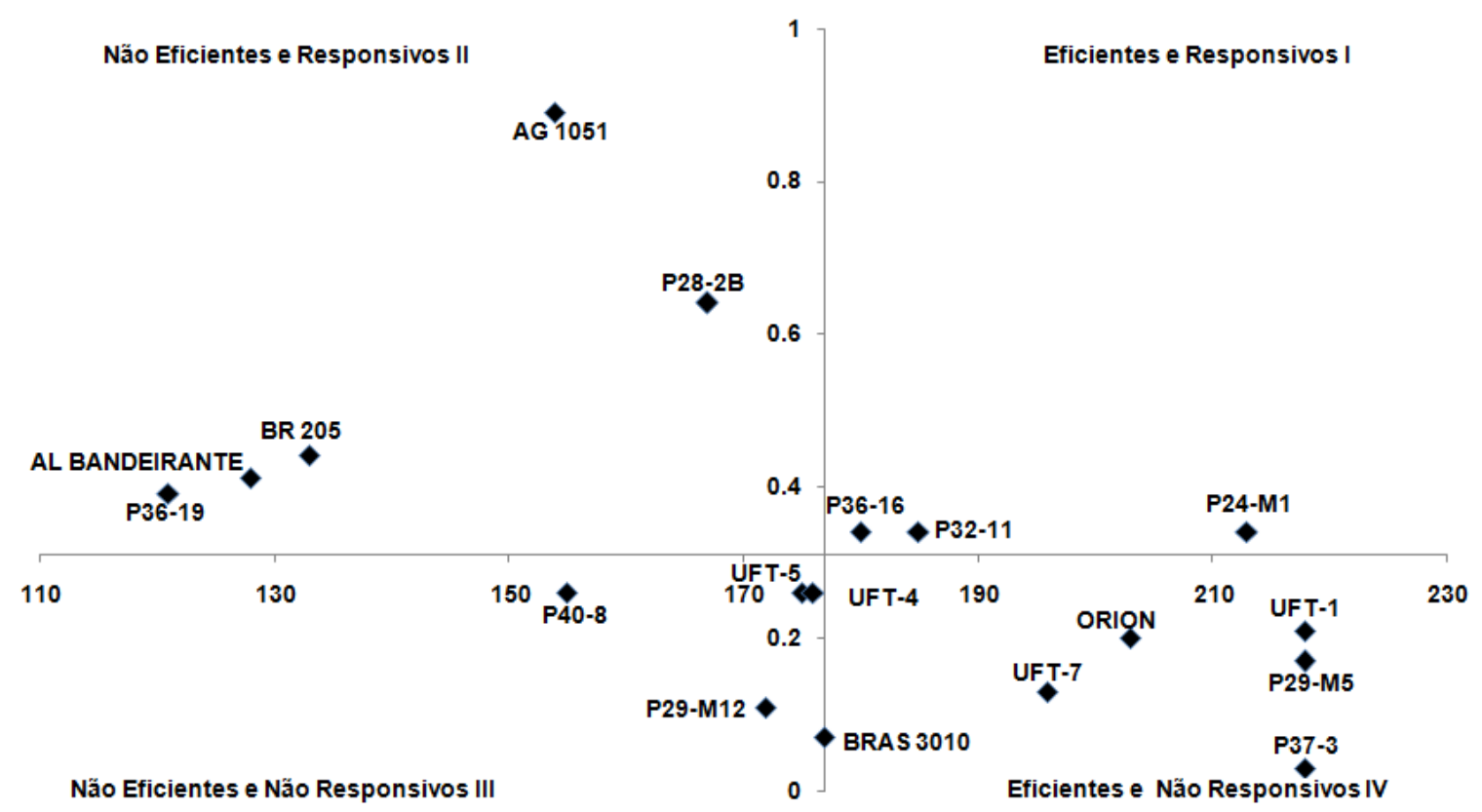

Figura 1. Eficiência no uso e resposta à aplicação de nitrogênio em genótipos de milho. 
Pelo teste realizado, os genótipos mais eficientes foram ORION, P37-3, P24M1, P29-M5, UFT 1 e UFT 7 e os menos eficientes P36-19, BR 205 e AL BANDEIRANTE.

As diferenças apresentadas entre os genótipos, em relação aos demais, na absorção e utilização de $\mathrm{N}$ no $\mathrm{RO}$, pode ser explicada pela expressão ou não expressão dos alelos favoráveis presentes nos genótipos, que resultam em uma melhor absorção e aproveitamento do $\mathrm{N}$ no desenvolvimento da planta.

Estes resultados estão em concordância com aqueles obtidos por Fidelis et al. (2008), Bueno et al. (2009), Santos et al. (2010), Cancellier et al. (2011), Soares et al. (2011), Kappes et al. (2013) e Silva et al. (2015) que também verificaram comportamento diferencial de genótipos de milho quando submetidos à níveis de $\mathrm{N}$.

Quanto a resposta à aplicação de $\mathrm{N}$, oito genótipos (P36-19, BR 205, AL BANDEIRANTE, AG 1051, P28-2B, P3616, P32-11 e P24-M1 destacaram-se por apresentarem os maiores índices, estando, portanto, representados no primeiro e segundo quadrantes (Figura 1). Destes, merecerem destaque o híbrido duplo AG 1051 e a variedade de polinização aberta P28-2B que apresentaram, respectivamente, valores de índice de resposta de 0,89 e 0,64 (Tabela 2).

Ressalta-se que P36-16, P32-11 e P24-M1 além de responsivos, são eficientes quanto ao uso do $\mathrm{N}$ em ambientes com baixo nível do mesmo $(\mathrm{BN})$, o que demonstra adaptação destes materiais em ambientes de baixa e alta disponibilidade de $\mathrm{N}$ (primeiro quadrante da Figura 1).

Por outro lado, os genótipos P36-19, BR 205, AL BANDEIRANTE, AG 1051 e P28-2B por terem apresentado baixo RO em $\mathrm{BN}$ foram considerados como não eficientes, porém tiveram caracterizado suas condições de materiais responsivos (segundo quadrante da Figura 1). Estes genótipos são indicados para serem utilizados por agricultores que dispõem de nível tecnológico elevado.

Os genótipos P40-8, P29-M12, UFT 5 e UFT 4 por terem apresentado baixo rendimento de óleo no ambiente $\mathrm{BN}$ (inferior à média dos genótipos, ou seja, $177 \mathrm{~kg} \mathrm{ha}^{-1}$ ) e também por terem apresentado baixos índices de resposta a aplicação de N (inferior a 0,31) foram considerados como não eficientes e não responsivos (terceiro quadrante da Figura 1). Genótipos deste quadrante não são recomendados para semeaduras em propriedades agrícolas, nem mesmo para aquelas que utilizam baixo nível tecnológico. 


\section{CULTIVO PARA ALTO E BAIXO NITROGÊNIO EM GENÓTIPOS DE MILHO NO TOCANTINS VISANDO A PRODUÇÃO DE ÓLEO}

Os genótipos UFT 7, ORION, UFT 1, P29-M5 e P37-3 por terem apresentado alto RO no ambiente BN (acima da média geral, ou seja, $177 \mathrm{~kg} \mathrm{ha}^{-1}$ ) e também por terem apresentado baixos índices de resposta a aplicação de $\mathrm{N}$ (inferior à média geral 0,31) foram considerados como eficientes e não responsivos (quarto quadrante da Figura 1). Os genótipos deste grupo são recomendados para o cultivo em propriedades que adotam baixo nível tecnológico.

Pelo teste de Scott \& Knott (1974), a $5 \%$ de significância (Tabela 1), o híbrido AG 1051 apresentou a melhor resposta, seguido pelas variedades P28-2B, P36-19, BR 205 e AL BANDEIRANTE. Os genótipos menos responsivos foram P29-M12, BRAS 3010 e P37-3.

A correlação entre os índices de eficiência e os índices de resposta dos genótipos foi negativa e significativa $(r=$ 0,55, p<0,05), indicando que os genótipos mais eficientes foram, de modo geral, menos responsivos, fato este também confirmado pelo teste de Scott \& Knott (1974) (Tabela 1). Tal resultado de certo modo era esperado, uma vez que genótipos desenvolvidos para uma condição favorável (ex: AN), ou seja, onde o nível tecnológico empregado seja alto, dificilmente serão eficientes sob condições de estresse (ex: BN). De modo similar, genótipos desenvolvidos para condições de estresse, serão eficientes nesta condição, mas pouco responsivos.

\section{CONCLUSÕES}

Considerando a resposta à aplicação de N, o híbrido duplo AG 1051 e a variedade de polinização aberta $\mathrm{P} 28-2 \mathrm{~B}$, são os mais responsivos. $\mathrm{E}$ os genótipos menos responsivos são P29-M12, BRAS 3010 e P37-3.

Os genótipos UFT 7, ORION, UFT 1, P29-M5 e P37-3 são recomendados para o cultivo em propriedades que adotam baixo nível tecnológico.

Os genótipos P36-19, BR 205, AL BANDEIRANTE, AG 1051 e P28-2B, são indicados para agricultores que dispõem de nível tecnológico elevado.

\section{REFERÊNCIAS}

ALBUQUERQUE, A.W.; SANTOS, JOSÉ R.; MOURA FILHO, G.; REIS, L.S. 2013. Plantas de cobertura e adubação nitrogenada na produção de milho em sistema de plantio direto. Revista Brasileira de Engenharia Agrícola e Ambiental, Campina Grande, v.17, n.7, p.721-726.

BUENO, L.G.; CHAVES, L.J.; OLIVEIRA, J.P.; BRASIL, E.M.; REIS, A.J.S.; ASSUNÇÃO, A.; PEREIRA, A.F.; RAMOS, M.R. 2009. Controle genético do teor proteico nos grãos e de caracteres agronômicos em milho cultivado com diferentes níveis de adubação 
nitrogenada. Pesquisa Agropecuária Brasileira, Brasília, v.44, n. 6, p. 590598.

CANCELLIER, L.L.; AFFÉRRI, F.S.; CARVALHO, E.V.; DOTTO, M.A.; LEÃO, F.F. 2011. Eficiência no uso de nitrogênio e correlação fenotípica em populações tropicais de milho no Tocantins. Revista Ciência Agronômica, Fortaleza, v.42, p.139-148.

CARDOSO, M.J.; SOBRINHO, C.A. 2007. O milho no Meio-Norte do Brasil: estratégias básicas do manejo. Teresina: Embrapa Meio-Norte, 384p.

CONAB - Companhia Nacional de Abastecimento. 2015. Acompanhamento da Safra Brasileira de Grãos, v. 2 Safra 2014/15, n. 9. Brasília: CONAB, 2015. 138p. Disponível em: <http://www.conab.gov.br/OlalaCMS/upl oads/arquivos/15_06_11_09_00_38_bolet im_graos_junho_2015.pdf>. Acesso em: 3 Set. 2015.

CRUZ, C.D. 2007. Programa Genes: Aplicativo computacional em genética e estatística. Viçosa: UFV, 442p.

CRUZ, C.D.; FERREIRA, F.M.; PESSONI, L.A. 2011. Biometria aplicada ao estudo da diversidade genética. Visconde do Rio Branco: Suprema, 620p.

FAGERIA, N.K.; BALIGAR, V.C. 1993. Screening crop genotypes for mineral stresses. In: Workshop on adaptation of plants to soil stresses, 1993, Lincoln. Proceedings... Lincoln: University of Nebraska. (Intsormil Publication, 94-2).

FANCELLI, A.L.; DOURADO NETO, D. 2004. Produção de milho. 2 ed. Piracicaba: Livroceres, 360p.

FIDÉLIS, R.R.; AFFERRI, F.S.; PELUZIO, J.M.; SANTOS, G.R.; LEMUS, E.A.E. 2008. Classificação de populações de milho quanto a eficiência e resposta ao uso de fósforo em solos naturais de cerrado. Bioscience Journal, Uberlândia, v.24, n.3, p.39-45.
FIDELIS, R.R.; ROTILI, E.A.; SANTOS, M.M.; BARROS, H.B.; MELO, A.V.; DOTTO, M. 2011. Eficiência no uso de nitrogênio em cultivares de arroz irrigado. Revista Brasileira de Ciências Agrárias, Recife, v.6, n. 4, p.622-626.

FIDELIS, R.R.; ROTILI, E.A.; SANTOS, M.M.; BARROS, H.B.; RODRIGUES, A.M. 2012. Eficiência quanto ao uso e resposta à aplicação de nitrogênio de cultivares de arroz em solos de terras altas no Sul do Estado de Tocantins, safra 2007/2008. Bioscience Journal, Uberlândia, v.28, n.3, p.432-438.

FRITSCHE-NETO, R.; BORÉM, A. 2011. Melhoramento de plantas para condições de estresses abióticos. Visconde do Rio Branco: Suprema, 250p.

GAZOLA, D.; ZUCARELI, C.; SILVA, R.R.; FONSECA, I.C.B. 2014. Aplicação foliar de aminoácidos e adubação nitrogenada de cobertura na cultura do milho safrinha. Revista Brasileira Engenharia Agrícola e Ambiental, Campina Grande, v.18, n.7, p.700-707.

IAL. Instituto Adolfo Lutz. 2005. Normas analíticas do instituto Adolfo Lutz. Métodos químicos e físicos para análise de alimentos. São Paulo: IAL, 317 p.

KAPPES, C.; ARF, O.; ANDRADE, J.A.C. 2013. Produtividade do milho em condições de diferentes manejos do solo e de doses de nitrogênio. Revista Brasileira de Ciência do Solo, Viçosa, v.37, p.1310-1321.

PIMENTEL-GOMES, F. 2009. Curso de estatística experimental. $15 . \quad \mathrm{ed}$. Piracicaba: FEALQ, 451p.

ROTILI, E.A.; FIDELIS, R.R.; SANTOS, MANOEL, M.; BARROS, H.B; PINTO, L.C. 2010. Eficiência do uso e resposta à aplicação de fósforo de cultivares de arroz em solos de terras altas. Bragantia, Campinas, v.69, n.3, p. 705-709.

SANTOS, M.M.; GALVÃO, J.C.C.; SILVA, I.R.; MIRANDA, G.V.; FINGER, F.L. 2010. Épocas de aplicação de nitrogênio 
em cobertura na cultura do milho em plantio direto, e alocação do nitrogênio $\left(\mathrm{N}^{15}\right)$ na planta. Revista Brasileira de Ciência do Solo, Viçosa, v.34, p.11851194.

SANTOS, W.F.; PELUZIO, J.M.; AFFÉRRI, F.S.; SODRÉ, L.F.; SANTOS, D.S.; FARIAS, T.C.M. 2014. Variabilidade genética e eficiência de uso do nitrogênio em populações de milho para teor de óleo. Amazonian Journal of Agricultural and Environmental Sciences, Belém, v.57, p.312-317.

SANTOS, W.F.; PELUZIO, J.M.; SODRÉ, L.F.; AFFÉRRI, F.S.; OLIVEIRA, K.J.C.; ARAUJO, L.L. 2015. Épocas de semeadura, doses de nitrogênio e rendimentos de óleo em populações de milho. Tecnologia \& Ciência Agropecuária, João Pessoa, v.9, n.1, p.29-32.

SCOTT, A.; KNOTT, M. 1974. A cluster analysis method for grouping means in the analysis of variance. Biometrics, Washington, v.30, p.507-512.

SILVA, K.C.L.; SILVA, K.P.; CARVALHO, E.V.; ROTILI, E.A.; AFFÉRRI, F.S.; PELUZIO, J.M. 2015. Divergência genética de genótipos de milho com e sem adubação nitrogenada em cobertura. Revista Agro@mbiente On-line, Boa Vista, v.9, n.2, p.102-110.

SOARES, M.O.; MIRANDA, G.V.; GUIMARÃES, L.J.M.; MARRIEL, I.E.; GUIMARÃES, C.T. 2011. Parâmetros genéticos de uma população de milho em níveis contrastantes de nitrogênio. Revista Ciência Agronômica, Fortaleza, v.42, p.168-174.

Recebido em: 17/10/2015

Aceito para publicação em: 28/7/2016 